\title{
CULTURE, HISTORY AND TRAUMATIC MEMORY: AN INTERPRETATION ${ }^{1}$
}

\begin{abstract}
Allan Young ${ }^{2}$
Abstract: Efforts to investigate psychiatric disorders across cultures routinely ignore a pervasive cultural influence, namely the culture of psychiatry. This article focuses on how the culture of psychiatry affects our understanding of posttraumatic stress disorder (PTSD). PTSD is diagnosed by means of standardized symptom criteria and scales. Yet it is a heterogeneous phenomenon. The illusion of homogeneity is fostered by a categorical conception of traumatic memory that homogenizes posttraumatic memories and erects an obstacle to investigating the disorder's historical nature, clinical phenomenology, and neuro-physiology and neuro-anatomy. I illustrate this process, via an epidemic of PTSD that now affects a quarter of a million American war veterans.
\end{abstract}

Key words: posttraumatic stress disorder, mental health, culture, psychiatry

\section{Cultura, historia y memoria traumática: una interpretación}

Resumen: Los esfuerzos para investigar trastornos psiquiátricos a través de las culturas, por lo general ignoran una frecuente influencia cultural, que es la propia cultura de psiquiatría. Este artículo se enfoca en cómo la cultura de psiquiatría afecta nuestro entendimiento del trastorno de estrés post-traumático (TEPP). El TEPP se diagnostica mediante criterios de síntomas y escalas. No obstante, es un fenómeno heterogéneo. La ilusión de homogeneidad es fomentada por una concepción categórica de memoria de trauma que homogeneiza las memorias post-trauma y crea un obstáculo para investigar la historia natural del trastorno, la fenomenología clínica, neurofisiología y neuroanatomía. Ilustro este proceso por medio de una epidemia de TEPP que afecta a un cuarto de millón de veteranos de guerra en Norteamérica.

Palabras clave: trastorno de estrés postraumático, salud mental, cultura, psiquiatría

Cultura, história e memória traumática: uma interpretação

Resumo: Os esforços para investigar transtornos psiquiátricos em diferentes culturas rotineiramente ignoram a difusa influência cultural, principalmente a cultura da psiquiatria. Este artigo enfoca como a cultura da psiquiatria afeta a nossa compreensão do transtorno de estresse pós-traumático (PTSD). PTSD é diagnosticado por meio de critérios de sintomas padronizados e escalas. No entanto, é um fenômeno heterogêneo. A ilusão de homogeneidade é fomentada por uma concepçấo categórica da memória traumática que homogeniza as memórias pós-traumáticas e erige um obstáculo para investigar a natureza da desordem histórica, a fenomenologia clínica, e a neurofisiologia e neuroanatomia. Explico este processo por meio de uma epidemia de PTSD que atualmente afeta um quarto de um milhão de veteranos de guerra americanos.

Palavras-chave: transtorno de estresse pós-traumático, saúde mental, cultura, psiquiatria

\footnotetext{
${ }^{1}$ A paper originally prepared for simposio "Salud Mental Global: perspectivas socioculturales y éticas", 11-12 de enero de 2016, Clínica Psiquiátrica Universitaria, Universidad de Chile, Santiago de Chile, in collaboration with the Departamento de Psiquiatría de McGill University (División de Psiquiatría Social y Transcultural).

${ }^{2}$ Departamento de Psiquiatría de McGill University (División de Psiquiatría Social y Transcultural), Canadá

Correspondence: allan.young@mcgill.ca
} 


\section{What is PTSD?}

The question is straightforward but best approached indirectly, through PTSD's most important manifestations:

1. DSM and ICD symptom lists, regarded as sufficient for making differential diagnoses.

2. 'Pure' cases: flesh-and-blood individuals whose symptoms are unambiguous, overt (not simply inferred), and uncompromised by co-morbid disorders such as depression, anxiety disorder, and alcohol or chemical substance abuse.

3. Cases in which the distinctiveness of symptoms is complicated by co-morbid disorders and contestable traumatic events. The majority of research on PTSD has been conducted on the 'chronic' subtype, where symptoms have lasted six months or longer, and the great majority of chronic cases correspond to this third kind.

4. Epidemiological populations, in which cases are aggregated and symptoms decomposed to plot distributions and correlations.

The four manifestations are conventionally assumed to be congruent, but the assumption is problematic. In reality, the manifestations are connected by "family resemblances": they overlap rather than converge. The pervasive misperception is a consequence of the culture of psychiatric science. Resistance to the idea that psychiatry might have a culture is grounded in a false dichotomy that separates psychiatric science from psychiatric culture. My use of the term 'culture' refers to a system of tacit meanings, dispositions (values, sentiments), pragmatics (ways of knowing what to do or say next), and self-confirming outcomes in research and the clinic. The common understanding is that culture and psychiatry are linked only externally: e.g. the idea that the posttraumatic syndrome is represented differently in different cultures, each reflecting the local idioms of distress. The alternative possibility is ignored: the existence of a culture intrinsic to the operations of psychiatric science and the manifestations of traumatic memory.
Every diagnostic classification has a history, but PTSD is historical in an additional sense. The engagement between trauma and history over the last two centuries comprises multiple 'episodes' that follow a common pattern. Each episode started with an event of encompassing violence and an epidemic of posttraumatic casualties. The epidemics were sources of controversy regarding the numbers affected, their etiology, impairment, and differential diagnosis; the distribution of culpability and obligation for these casualties; the economic and social costs of fulfilling those obligations; and the appropriate intervention strategies. Resources were mobilized (manpower, technologies, facilities) for managing casualties, claimants, and research. In each episode, a distinctive assemblage emerged, colored by national medical traditions, institutional cultures, and popular attitudes. Now familiar syndromes shellshock, PTSD, mild traumatic brain injury (mTBI), Gulf War Syndrome, second-generation Holocaust trauma, etc. - and subjectivities (victims' self-awareness, and self-representations) incubated within these cultural-historical assemblages. PTSD is incorrectly perceived as a timeless phenomenon. It as a 'form of life', shaped by culture, historical contingency, and locality.

\section{Malleable Memories}

The structure of PTSD has remained unchanged from DSM-III onward. In plain English, an event creates a memory that is immediately or belatedly distressful, repetitive, and intrusive (involuntary). Remembering traumatic memories mobilizes an autonomic nervous system response, resulting in difficulty sleeping, irritability, exaggerated startle response, hypervigilance, difficulty concentrating, and motor restlessness. The patient adapts to the distressful memory and consequent arousal through symptomatic forms of avoidance and numbing. In short, we are talking about a classic neurotic adaptation.

The earliest descriptions of memory-driven posttraumatic disorders date to the 1870s and1880s, and refer to cases involving pseudo-neurological symptoms. Jean-Martin Charcot referred to these memories as "mental parasites," and this conception recurs in the writings of Pierre Janet and Sigmund Freud on traumatic neurosis and traumatic 
neurasthenia. One of the earliest descriptions of a clinical case concerns a Parisian identified as "Lelog." According to Le-log, he was knocked down in the street by a runaway horse and wagon, and the wagon wheels ran over his thighs. Le-log lost consciousness: on awakening, he discovered livid bruises across his thighs and that his legs were paralyzed. Le-log was then brought to Charcot, a celebrated neurologist. The account given in most histories of PTSD stops at this point. But there is more to the story, for onlookers informed Charcot that Le-log collapsed before the wagon reached him and the wheels did not roll over his legs. Charcot conclusion was that Le-log's recollection was not a memory of a past event but a memory of the future, anticipating an event he believed was going to happen. When, on recovering consciousness, Le-log saw his bruises, his fears were confirmed. Charcot's conclusion was that memories of this sort might be as toxic as the real thing, i.e. memories of the past. If reliable eyewitnesses are present, there is no problem distinguishing between the two kinds of memory. Otherwise, a physician must depend on his intuition.

During World War One, German army physicians, including Max Nonne and Fritz Kaufmann, claimed that most cases of traumatic hysteria affecting front-line soldiers were the consequence of memories of the future. Sigmund Freud identified a related etiological pathway, referring to it as Nachträglichkeit. A harmless event is belatedly transformed into a troubling memory when its traumatic meaning is discovered. The pathway to this toxic memory leads from the onset of non-specific symptoms to the discovery of an event initially misunderstood as non-toxic, thus reversing the pathway that is typical of traumatic neuroses. The remembered experience is more than an attribution: it is not simply recalled, but actively re-experienced in intrusive thoughts, images, and dreams, acquiring the emotional power and psychological salience of a traumatic event.

There are two additional ways in which the iconic traumatic memory is imitated. Number one is factitious memory, where someone develops an intense psychological identification with a borrowed or imagined etiological event; more commonly, it is identified with a grossly distorted representation of an autobiographical event.
Factitious memory is often described as a form of self-deception, but it equally tokens un-selfconscious efforts aimed at salvaging or rebuilding the individual's sense of self. Number two is fictitious traumatic memory or malingering. By definition, a malingerer is aware of dissimulating and there is no self-deception. In practice, the boundary between fictitious and factitious memories is porous, and easily transgressed via autosuggestion - a subject of intense interest to trauma doctors a century ago, but for the wrong reasons no longer considered interesting.

To summarize, I have cited five kinds of traumatic memory: iconic memory, memory of the future, Nachträglichkeit, factious memory, and malingering. In each instance, memories are represented as if they were object-like things, stored in a librarylike mental location, waiting to be retrieved. An idea still popular among PTSD researchers is that traumatic memories are also uniquely 'indelible', analogous to videotapes and DVDs. Yet there is no compelling empirical evidence that traumatic memories are unlike other memories in this respect(1). All episodic memories are intrinsically malleable. In his famous 1932 monograph, Remembering, the British psychologist Fredrick Bartlett suggested that memories enter consciousness via a process, in which mnemonic traces of an experience are re-assembled, recalibrated, updated, and re-schematized. Re-assembly draws on semantic memory (substantive knowledge) and fragments of other, associated episodic memories, and affected by the individual's mental state and life situation. Thus memories - the product that enters consciousness- are intrinsically malleable.

This process has been intensively studied during the intervening years. Cognitive neuroscience portrays malleability as evidence of memory's evolutionary origin and function. Memories of the past are simultaneously memories for the future: a means of enhancing the organism's ability to respond to new situations, rather than a medium for providing faithful photocopies of the past. Memories provide the templates we depend on for interpreting novel and ambiguous events, but the templates are themselves reshaped for each occasion $(2,3)$. 
The malleability of memory is illustrated by a seminal study of American veterans $(\mathrm{n}=59)$ of the first Gulf $\operatorname{War}(4)$. The men were interviewed one month after returning from the theater of operations, and re-interviewed two years later. On both occasions, the men completed a 19-item questionnaire keyed to their combat experiences. In the second interview, $70 \%$ of the men reported experiencing at least one combat event that had not been reported in the initial interview. The most commonly reported newly remembered events were "bizarre disfiguration of bodies as a result of wounds," "seeing others killed or wounded," and "extreme threat to your personal safety." The researchers emphasize that the majority of newly remembered experiences concern "objectively described severe events," rather than "subjectively evaluated experiences." The second interview also provided evidence of forgetting: $46 \%$ of the respondents failed to report one or more of the events that they had reported one month after returning home.

Researchers traced the previously unreported experiences were traced to two sources. First, during the interval between interviews, men typically viewed media accounts of the military actions in which they participated, and had conversations with other veterans about their Gulf War experiences. The images and narratives absorbed during this period were a source of factitious memories. "(I)ndividuals who became increasingly symptomatic over time unknowingly exaggerated their memory for trauma events as a way to understand or explain their emerging psychopathology" (4:176). And researchers pointed to a positive correlation between number of PTSD symptoms and number of new events reported by the participants in the study.

The malleability or fluidity of traumatic memory is the outward manifestation of an underlying neuropsychological process, connecting manifestations of traumatic memory - iconic, factitious, fictitious - that penetrate into consciousness over the course of time.

\section{A Puzzling Epidemic}

US military veterans comprise the largest global population currently diagnosed with PTSD. In
December 2004, the Chicago Sun-Times reported significant disparities in PTSD compensation for Illinois veterans and recipients elsewhere. Illinois ranked last among the states, and its congressional delegation wanted the Dept. of Veterans Affairs to explain the discrepancy. Its report, published in 2007, outlined the national context: disability rolls for PTSD grew from 120,265 recipients @ $\$ 1.7$ billion (1999) to 215,871 @ $\$ 4.3$ billion (2004)(5:vii). The trend has continued: by 2014, over 650,000 veterans were receiving compensation for PTSD. This development is explained in part by the massive expansion of the operational theater in the Middle East following the Gulf War and the invasions of Afghanistan and Iraq, and adding two million more US veterans by 2015 .

Additional factors favoured this trend. In 2010, it became significantly easier for a veteran to qualify for PTSD diagnosis and a 'service-connected' disability claim. The claim requires evidence of an experience (a 'stressor') sufficient to precipitate the posttraumatic syndrome. From 1980 (DSMIII) to 2010 , stressors were limited to witnessing or experiencing traumatic events. In 2010, the VA expanded the range of stressors to include a victim's fear or expectation of an imminent trauma-level event. In other words, it was no longer necessary to suffer or witness traumatic violence directly. In 2012, the requirement that claimants document physical proximity to stressors was set aside. Following these changes, PTSD claims rose $60 \%$ to over 150,000 per annum, and the approval rate increased from $55 \%$ to $74 \%$ (6).

A quarter million Vietnam War veterans were added to PTSD disability rolls after 2001. In most cases, this means a 40-year delay between the veterans' traumatic events and the diagnosis of their PTSD syndrome. Where the delay between traumatic event and onset of symptoms exceeds 6 months, cases are considered to be "delayed expression" or "delayed onset" PTSD. The period that precedes the onset of PTSD in these cases can be symptom-free or characterized by unexplained symptoms (somatic, behavioural). When traumatic experiences are subsequently recalled, the previously unexplained symptoms are characteristically recognized (post hoc) as posttraumatic. 
Frueh et al.(7) analyzed data on 747 veterans treated in VA primary care clinics, and structured clinical interviews collected from a sub-sample of 150 veterans. Cases included current PTSD, sub-threshold PTSD (individual symptoms that could be attributed to a traumatic stressor), and lifetime PTSD (associated with varied stressors in the past). In over $90 \%$ of cases, onset of PTSD symptoms had occurred within one month of the war-time trauma, and no onset occurred later than six years post-trauma. The inconsistency between these circumstances and the post-2001 explosion of late-onset PTSD among disability claimants is puzzling given that these veterans had continuous access to PTSD diagnosis and treatment from the VA since the 1980s.

One might hypothesize that the neurological changes that affect aging brains have contributed to this surge of late-onset PTSD. The idea here is that soldiers were exposed to traumatic stressors in Vietnam, but could regulate emotions and employ adaptive coping responses, notably suppression, after returning to the USA. Cognitive decline linked to aging, specifically the weakening of functional connections between prefrontal cortex, hippocampus, and other parts of the brain, would reduce the veteran's capacity to inhibit intrusive traumatic memories and regulate emotions. The process would lead to the re-emergence of PTSD symptoms and intense feelings of anxiety and depression $(8,9)$. This thesis explains the association between dementias and distressful intrusive memory in selected clinical populations, but it does not map the age-adjusted epidemiology of the surge in late-onset PTSD. Empirical research published in the American Journal of Geriatric Psychiatry, based on a large sample veterans in VA primary care clinics, indicates that older veterans (at-risk for dementias) self-report fewer PTSD symptoms and better mental health than do younger veterans(10).

\section{Malingering and PTSD}

Thus two highly respected PTSD researchers, McNally and Frueh, were led to conclude that "financial need, not psychiatric disorder, is the primary driver of the skyrocketing rate of disability claims...," and they cite an analysis of a "massive federal dataset" by labor economists(11) showing that most claimants for PTSD disability awards are "veterans whose limited vocational skills reduce their ability to make a decent living" (12:524). In other words, the epidemic is a product of malingering, a conscious deception of others with the goal of obtaining a pension or other forms of secondary gain.

The malingering thesis is consistent with the findings of the VA's Office of the Inspector General. Patients diagnosed with PTSD typically get worse (more symptomatic), but continue to attend treatment sessions. The disability rating (and therefore compensation) increased over time, until reaching a maximum (100 percent), at which point the typical patient "sought less treatment for the condition. ... The average decline in visits was 82 percent... (While) mental health visits declined, non-mental health visits did not"(5:52).

PTSD is a perfect medium for malingering. Key symptoms such as intrusive images and disturbing dreams are subjective, self-reported and easily faked. And knowledgeable malingerers are able to produce putative biomarkers such as elevated heart rate and abnormal responses to Stroop Tests. Interest in malingering has waxed and waned: during the late $19^{\text {th }}$ century it focused on compensation claims for injuries suffered in railway accidents; interest reemerged during World War I, when shellshock symptoms provided soldiers a way to escape from the trenches. Popular interest in malingering revived again in the 1990s, attracted by florid narratives based on "recovered memory." Malingering received relatively little attention in psychiatric journals immediately prior to the publication of DSM-III - averaging just two or three papers per annum. Following the introduction of a PTSD diagnosis (1980) and redefinition of malingering as the product of false or exaggerated symptoms, motivated by external incentives (1987), publications multiplied. By 2010, the annual average hovered around 100(13:296).

Malingering is interpreted variously, as either a categorical or dynamic phenomenon. The DSMs provide psychiatry with a categorical phenomenon: a standard for dividing symptoms into false and authentic. The dynamic perspective sees malingering as a psychological process, pairing he 
malingerer's conscious effort to deceive someone with his effort - conscious or unconscious - to deceive himself. Robert Trivers pursues the theme of other-deception and self-deception in a stream of books and articles beginning in the 1970s. His premise is that other-deception pervades all levels of life, down to the molecular determinants of living matter; successful deception must evade obstacles that evolved to thwart deception. Among humans, these evolved obstacles include the fear of being detected and the psychological cost of cognitive dissonance (conflict between someone's subjective and asserted beliefs, perceptions, motives, etc.). The immediate cost of deception is added time and effort; the ultimate cost can be the subversion of the spontaneity, body language, and self-possession that are widely associated with truthfulness.

Self-deception is a strategic adaptation to challenges emerging from other-deception. If we accept Trivers' account, this is not exceptional behaviour: it is habitual human behaviour. This is a supremely interesting argument, but not because of any moral implications (which do not concern Trivers). It is interesting because the core activity of self-deception concerns memory-work: a twofold effort, first, to revise or reconstruct the past via a combination of imagination or editing, and a second effort to identify with one's deception. The plausibility of Trivers' thesis has grown over the last two decades, in tandem with the continuing elaboration of the Bayesian Brain, the operations and reach of its Default Mode Network, and the clinical phenomenology of memories of the future.

\section{The Brain: a Bayesian Inference Machine?}

While considerable attention was given to the diagnostic significance of traumatic memory in the run-up to the publication of DSM-5 (2013), it focused mainly on the question of whether a memory criterion should be retained in PTSD's symptom list. Traumatic memories of the future were entirely ignored. This lack of interest on the part of experts is understandable however. Historical memory of the century-old debates that had begun with Charcot had faded, and current interest in memories of the future and underlying memory-system had only just begun, and in cog- nitive- and social-neuroscience rather than psychiatry. In addition, this memory system, once taken seriously, would token a paradigm shift, followed inevitably by the devaluation of vast amounts of symbolic capital accumulated, mainly in the USA, since the publication of DSM-III. But we have yet to introduce you to the futurethinking brain, also known as Bayesian brain and Helmholtzian brain.

This brain began with a puzzle, identified two decades ago. The human brain is a very expensive organ, accounting for $20 \%$ of the body's energy consumption. One might assume that energy consumption increases when the brain is engaged in stimulus-bound, goal-directed activity, yet consumption decreases. It increases in the 'default mode', as the brain attends to internal neuronal traffic and 'idle' activities that include mind-wandering, stimulus-free thought, autobiographical recollection, self-referential processing). Moreover, brain activity during these conditions is remarkably similar among individuals and between groups, so that researchers refer to a 'default mode network'.

The findings provoked the question: What is the brain doing when it is doing nothing? One solution, promoted by Karl Friston, is that the brain is dedicated to controlling 'free energy', defined as the consequence of prediction error, the failure of the brain to anticipate and order outcomes (see Apps and Tsakiris for a systematic review of publications relevant to psychiatry)(14). The freeenergy principle asserts that adaptive change in biological systems (including the central nervous system) aims to minimize surprise - that is, unpredicted and un-interpretable feedback. Failure to limit surprise leads to a progressive increase in entropy (disorder) and violates the foundations of self-organization that are basic to biological systems. The second law of thermodynamics contends that entropy is the fate of all closed systems. But Friston argues otherwise: the brain is a product of evolutionary adaptations, that these adaptations include the optimization of relations among neurons. Entropy is not the fate of the brain in the short-run. 
Thus the human brain conforms to two, complementary principles: an evolutionary principle that defines adaptation as reproductive success, and a functional principle that defines adaptation as control over free energy and postponement of entropy. From a functional perspective, the brain is an inference machine. Memories of the past are a means for adjusting the machine, reducing prediction error, by matching a predicted outcome to a recorded outcome and revising the prediction (for the future) to reflect the calculation. The process is recursive: the brain is never at rest, notwithstanding references to a 'resting state'. The so-called 'forward motion model', employed in cognitive and robotic sciences, operates in an analogous manner.

In contrast to the evolutionary adaptations that help us to survive immediate threats, the functional processes associated with the default mode network occur over long periods. "(We) spend most of our time directed away from the environment in processing modes that consolidate the past, stabilize brain ensembles, and prepare us for the future. Activity events supporting these (longterm) functions may be structured in ways fundamentally different from those we have gleaned by studying input-output relations under immediate experimental control"(15:1095). Empirical support for this line of reasoning and, by extension, the idea that traumatic memories are memories of the future that are enabled by memories of the past, can be found in current default mode research into schizophrenia and autism spectrum disorders.

In summary, 'free energy' is an index of disorder (entropy) and, by extension, pathology. The extent of free energy can be modeled mathematically, but not measured or visualized directly. Rather, it is inferred from images of the default mode network. I located and reviewed $26 \mathrm{fMRI}$ studies (conducted between 2004 and 2014) of connectivity in the default mode network. Individuals diagnosed with PTSD were compared with nor$\mathrm{mal}$ controls, and (occasionally) individuals with superficially similar psychiatric disorders, such as generalized anxiety disorder. Findings represented in these studies are generally similar, showing reduced connectivity in the PTSD group between brain regions identified with emotion (amygdala, posterior cingulated cortex), memory (hippocampus), and executive function (prefrontal cortex). The pattern is consistent with the free energy principle, and one can infer the (PTSD) brain's diminished ability to optimize predictions. This interpretation is rarely made explicit however.

\section{Conclusions}

When PTSD first appeared, in DSM-III (1980), it was imagined to be a normal response to extraordinary situations. This was a strategic interpretation, intended to eliminate the constitutional factors that could undermine the service-connected entitlements claimed by affected veterans. Seven years later (DSM-IIIR), the formula was reversed in response to epidemiological research indicating that PTSD is an unusual response to distressful situations that most people manage without pathological consequences. The change resurrected doubts regarding the diagnostic validity of chronic PTSD, whose symptoms are similar, if not identical, to its co-morbid disorders. One solution to this challenge would be evidence (biomarkers) of a pathogenesis distinctive to PTSD. These biomarkers would perform a double service, confirm PTSD's validity and eliminate cases of malingering and factitious memory.

Three decades after the publication of DSM-IIIR, we are still wait for convincing biomarkers. This paper provides an explanation and suggests a way to move forward: PTSD researchers might consider adding a new brain, based on the principle of "predictive coding" thus replacing or marginalizing categorical conceptions of memory. Second, researchers might consider shifting their perspective on PTSD from exclusion to inclusion: away from the idea that cases based on malingered or factitious memories are necessarily external to the clinical phenomenon that we call "PTSD". 
Culture, history, and traumatic memory: an interpretation - Allan Young

\section{References}

1. McNally RJ. Remembering Trauma. Cambridge, MA: Harvard Univ. Press; 2003.

2. Hardt, O, Einarsson, EO, Nader, K. A bridge over troubled water: reconsolidation as a link between cognitive and neuroscientific memory research traditions. Annual Review of Psychology 2010; 61: 141-67.

3. Schacter DL, Addis DR, Hassibis D, Martin VC, Spreng RN, Szpunar KK. The future of memory: remembering, imagining, and the brain. Neuron 2012; 76: 677-694.

4. Southwick SM, Andrew Morgan III CA, Nicolaou AL, Charney DS. Consistency of memory for combat-related traumatic events in veterans of Operation Desert Storm. American Journal of Psychiatry 1997; 154: 173-177.

5. VAOIG. Veterans Affairs Office of the Inspector General. Review of state variances in VA disability compensation payments. VAOIG Report 2005; 05-00765-137. Retrieved from http://www.va.gov/ foia/err/standard/requests/ig.html

6. Zarembo A. As disability awards grow, so do concerns with veracity of PTSD claims. Los Angeles Times 2014-08-03.

7. Frueh BC, Grubaugh AL, Yeager D E, Magruder KM. Delayed-onset posttraumatic stress disorder among veterans in primary care clinics. British Journal of Psychiatry 2009; 194: 515-520.

8. Grady CL, Furey ML, Pietrini P, Horwitz B, Rapoport SI. Altered brain connectivity and impaired short-term memory in Alzheimer's disease. Brain 2001; 124: 739-756.

9. Grossman AB, Levin BE, Katzen HL, Lechner S. PTSD symptoms and onset of neurologic disease in elderly trauma survivors. Journal of Clinical and Experimental Neuropsychology 2004; 26: 698-705

10. Frueh BC, Grubaugh AL, Acierno A, Elhai JD, Cain G, Magruder KM. Age differences in posttraumatic stress disorder, psychiatric disorders, and healthcare service use among veterans in Veterans Affairs primary care clinics. American Journal of Geriatric Psychiatry 2007; 15: 660-672.

11. Angrist JD, Chen SH, Frandsen BR. Did Vietnam veterans get sicker in the 1990s? The complicated effects of military service on self-reported health. Journal of Public Economics 2010; 94: 824-837.

12. McNally RJ, Frueh BC. Why are Iraq and Afghanistan War veterans seeking PTSD disability compensation at unprecedented rates? Journal of Anxiety Disorders 2013; 27: 520-526.

13. Berry DTR, Nelson NW. DSM-5 and malingering: A modest proposal. Psychological Injury and Law 2010; 3: 295-303.

14. Apps MAJ, Tsakiris M. The free-energy self: A predictive coding account of self-recognition. Neuroscience and Biobehavioral Reviews 2014; 41: 85-97.

15. Buckner RL, Vincent JH. Unrest at rest: default activity and spontaneous network correlations. Neuroimage 2007; 37 : 1091-1996.

\section{Bibliography}

Breslau N, Davis GC. Post traumatic stress disorder: The stresspr criterion. Journal of Nervous and Mental Disease 1987; 175: 255-264.

Coman A, Manier D, Hirst W. Forgetting the unforgettable through conversation: Socially shared retrieval-induced forgetting of September 11 memories. Psychological Science 2009; 20: 627-633.

Mullally SL, Maguire EA. Memory, imagination, and predicting the future: a common brain mechanism? The Neuroscientist 2014; 20: 220-234.

Von Hippel W, Trivers R. The evolution and psychology of self-deception. Behavioral and Brain Sciences 2011; 34 : 1-56. Young A. The Harmony of Illusions: Inventing Posttraumatic Stress Disorder. Princeton: Princeton University Press; 1995.

Young A, Breslau N. What is "PTSD”?: The Heterogeneity Thesis. In Hinton DG, Good GJ, eds. Culture and PTSD: Trauma in Global and Historical Perspective. Philadelphia, PA: Univ. of Pennsylvania Press; 2015: 135-154.

Received: February 2, 2016

Accepted: May 30, 2016 